\title{
Sistem Informasi Inventory Parfum Laundry CV. Wijaya Berbasis Web
}

\author{
Qoidatul Fadhilah $^{1 *}$, Nugroho Eko Budiyanto ${ }^{2}$ \\ ${ }^{1,2}$ Jurusan TEKNIK INFORMATIKA, Fakultas TEKNIK, Universitas Wahid Hasyim \\ Jl. Menoreh Tengah X/22 Sampangan Semarang 50236 \\ "E-mail: Qoidatulfadhilah@gmail.com
}

\begin{abstract}
Abstrak
CV. Wijaya Parfum Laundry merupakan salah satu perusahaan di bidang produksi dan distribusi parfum atau pewangi laundry yang berpusat di Yogyakarta dan memiliki banyak cabang seperti di Bogor, Bandung, Bali, Cirebon, Cilacap, Jember, Jakarta, Kediri, Malang, Puworkerto, Purworejo, Pekalongan, Surabaya, Tasik dan Wales. Saat ini sistem yang berjalan di CV. Wijaya Parfum Laundry masih menggunakan cara manual seperti pengecekan dan pencarian data parfum laundry yang dilakukan dengan cara manual sehingga mengalami kesulitan dan membutuhkan waktu yang lama dalam proses pengecekan dan pencarian data. Pencatatan di kertas atau buku dalam proses penambahan stok atau pengurangan stok. Hal ini mengakibatkan tidak efesien waktu dalam bekerja, sehingga membutuhkan waktu yang cukup lama. Dalam meningkatkan sistem berjalan dari CV Wijaya Parfum Laundry, penulis mengambil suatu solusi untuk membuat satu Sistem Informasi Inventory Parfum Laundry pada CV. Wijaya Parfum Laundry. Dalam proses perkembangan sistem usulan tersebut CV. Wijaya menggunakan bahasa pemprograman PHP versi 5 berbasis framework Codeigniter versi 3 dengan didukung HTML versi 5 dan CSS versi 3 untuk bagian tampilan User Interface (UI), sedangkan database yang digunakan adalah MySQL versi 5.
\end{abstract}

Kata Kunci : CodeIgniter, Inventory, Laundry, PHP, Yogyakarta

\section{PENDAHULUAN}

\subsection{Latar Belakang}

Persediaan merupakan bagian penting dalam proses operasional suatu perusahaan karena persediaan terdiri dari barang - barang yang dimiliki oleh perusahaan. Persedian bertujuan agar proses operasional dapat berjalan tepat waktu dan berjalan dengan lancar. Proses operasional yang tepat waktu dan lancar akan meningkatkan penjualan dan menghasilkan keuntungan yang besar. Persediaan digunakan baik pada perusahaan jasa, perusahaan produksi, maupun perusahaan distribusi. Dalam perusahaan produksi dan distribusi, persediaan akan dijual kembali tanpa mengubah bentuk dari barang tersebut.

Seiring perkembangan teknologi yang semakin canggih, membuat teknologi informasi saat ini menjadi sangatlah penting. Perkembangan teknologi sangatlah pesat sehingga memudahkan kita dalam mengelola, mencari data serta mendapatkan informasi. Sistem komputerisasi untuk saat ini sangat dibutuhkan oleh banyak perusahaan salah satunya perusahaan yang bergerak di bidang produksi dan distribusi pawangi atau parfum laundry.

Konsep dasar inventory (persediaan) setiap perusahaan, apakah perusahaan itu perusahaan perdagangan ataupun perusahaan pabrik serta perusahaan jasa selalu mengadakan persediaan. Tanpa adanya persediaan, para pengusaha akan dihadapkan pada resiko bahwa perusahaannya pada suatu waktu tidak dapat memenuhi keinginan pelanggan yang memerlukan atau meminta barang/jasa. Persediaan diadakan apabila keuntungan yang diharapkan dari persediaan tersebut hendaknya lebih besar dari pada biaya-biaya yang ditimbulkannya (Minarni, 2014).

Dengan merancang sistem kearah yang lebih baik diharapkan dapat membantu mempermudah untuk memproses sistem yang sedang berjalan sehingga memberikan kemudahan dalam mengolah data, memproses data, menyusun data, dan menyimpan data yang akhirnya menghasilkan data yang akurat yang dapat digunakan untuk keperluan perusahaan. Untuk itu, dibutuhkan suatu sistem informasi untuk mengatasi masalah tersebut. Sistem informasi yang dapat menginformasikan data dengan benar dan akurat.

CV. Wijaya Parfum Laundry merupakan salah satu perusahaan di bidang produksi dan distribusi parfum atau pewangi laundry yang berpusat di Yogyakarta dan memiliki banyak cabang seperti di Bogor, Bandung, Bali, Cirebon, Cilacap, Jember, Jakarta, Kediri, 
Malang, Puworkerto, Purworejo, Pekalongan, Surabaya, Tasik dan masih banyak cabang lainnya. Saat ini sistem berjalan di CV. Wijaya Parfum Laundry masih menggunakan cara manual seperti pengecekan dan pencarian data parfum laundry yang dilakukan dengan cara manual sehingga mengalami kesulitan dan membutuhkan waktu yang lama dalam proses pengecekan dan pencarian data. Pencatatan di kertas atau buku dalam proses penambahan stok atau pengurangan stok. Hal ini mengakibatkan tidak efesien waktu dalam bekerja, sehingga membutuhkan waktu yang cukup lama.

Berdasarkan permasalahan latar belakang diatas, maka penulis akan melakukan penelitian dan perancangan "Sistem Informasi Inventory Parfum Laudry CV. Wijaya berbasis Web". Sistem ini dapat memudahkan proses pengecekan persediaan barang, pendataan barang masuk dan barang keluar sehingga sistem yang akan dibangun dapat memudahkan karyawan dalam melakukan pekerjaannya.

\subsection{Batasan Masalah}

Adapun batasan masalah dari penelitian tersebut. Berikut adalah batasan masalahnya:

a. Sistem yang dibangun meliputi proses pemesanan, transaksi barang masuk dan barang keluar.

b. Sistem yang dibangun menggunakan bahasa pemograman PHP dengan framework CodeIgniter.

c. Sistem yang dibangun berbasis website.

\subsection{Tujuan Penelitian}

Adapun tujuan dari penelitian ini adalah sebagai berikut:

a. Untuk mengetahui sistem berjalan pada CV. Wijaya Parfum Laundry

b. Untuk merancang Sistem Informasi Inventory Parfum Laundry yang sesuai dengan permasalah pada $\mathrm{CV}$. Wijaya agar mempermudah karyawan dalam proses pengecekan barang, pendataan barang masuk dan barang keluar

\section{TINJAUAN PUSTAKA}

Beberapa penelitian mengenai sistem informasi inventory pernah dilakukan oleh beberapa peneliti. Dwitama (2017) dalam penelitiannya analisis dan perancangan sistem informasi terkomputerisasi pada sistem persediaan perusahaan jasa laundry (studi kasus pada Garden Eco Laundry). Penelitian ini dilakukan atas dasar banyak perusahaanperusahaan besar yang sudah menggunakan sistem terkomputerisasi dalam mengontrol persediaan perusahaan. Sistem dan prosedur persediaan yang baik akan menghasilkan informasi yang akurat bagi penggunanya. Garden Eco Laundry merupakan salah satu perusahaan jasa yang bergerak dalam bidang laundry di Surabaya. Peneliti melakukan analisis pada sistem dan prosedur persediaan Garden Eco Laundry yang memiliki beberapa kekurangan sehingga menimbulkan masalah. Metode penelitian yang digunakan adalah penelitian deskriptif dengan menggunakan pendekatan studi kasus dan teknik analisis data yang digunakan dimulai dari melakukan analisis prosedur, mengevaluasi, serta melakukan perancangan sistem informasi. Perancangan sistem informasi terkomputerisasi ini terdiri dari perancangan akses, database, input, dan output. Hasil penelitian ini berupa rancangan sistem informasi persediaan secara terkomputerisasi dan perbaikan prosedur perusahaan. Dari hasil penelitian ini, diharapkan perusahaan mau menerapkan prosedur yang baru serta sistem informasi terkomputerisasi pada sistem persediaan perusahaan guna meminimalisir permasalahan yang ada di perusahaan.

Penelitian mengenai sistem informasi inventory juga pernah dilakukan oleh Sukamdana (2011) mengenai Perancangan sistem informasi inventory berbasis web pada PT. Citra Gemilang Prima. Terdapat masalah dalam perusahaan tersebut, yaitu pencatatan persediaan yang dilakukan masih menggunakan cara manual. Sehingga perusahaan tersebut mengalami kendala dalam proses pengolahan data barang di gudang. Metode dalam alur persediaan menggunakan metode FIFO (First In First Out). Metode yang digunakan dalam perancangan Sistem Informasi Inventory Berbasis Web pada PT. Citra Gemilang Prima, serta untuk mengetahui sistem yang sedang berjalan, menggunakan metode analisis PIECES, sedangkan untuk metode pengembangan sistemnya menggunakan metodologi XP (eXtreme Programing). Perangkat lunak pendukung yang digunakan adalah Adobe Dreamweaver CS 6, Xampp, database MySQL. Dengan adanya sistem berbasis web ini, yang sudah terkoneksi dengan database, tentunya akan sangat mempermudah pengolahan data barang dalam gudang dan akan 
sangat membantu sekali dalam hal proses keluar masuk barang ke dalam gudang.

\section{METODE PENELITIAN}

Dalam penelitian ini metode yang digunakan dalam pengembangan sistem informasi yaitu System Development Life Cycle dengan model waterfall. Pada metode ini menawarkan cara pembuatan sebuah perangkat lunak yang melakukan pengerjaan suatu sistem secara berurutan. Menurut (Ladjamudin Al-Bahra, 2006:154) model ini menawarkan cara pembuatan perangkat lunak secara lebih nyata. Langkah-langkah yang penting dalam model ini adalah :

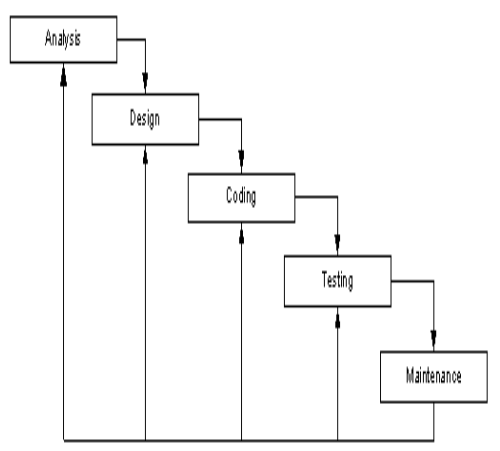

Gambar 1 Metode SDLC

\section{HASIL DAN PEMBAHASAN}

Use case diagram adalah rangkaian/ uraian yang saling terkait dan membentuk sistem secara teratur dan terdapat aktor atau pengguna sistem. Menurut Connolly (2011: 72) Use Case Diagram merupakan rangkaian tindakan yang dilakukan oleh sistem, aktor mewakili user atau sistem lain yang berinteraksi dengan sistem yang dimodelkan.

\subsection{Use Case Diagram Admin}

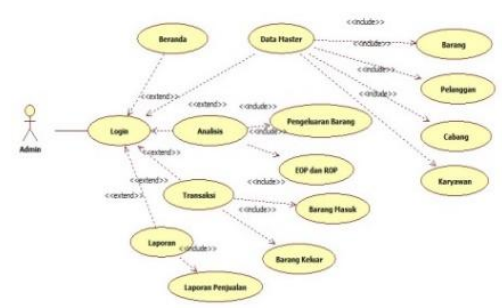

Gambar 2. Use Case Diagram Admin

\subsection{Use Case Diagram Karyawan}

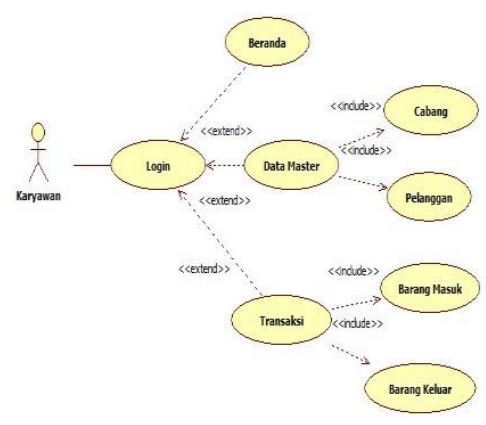

Gambar 3. Use Case Diagram Karyawan

\subsection{Use Case Diagram Pelanggan}

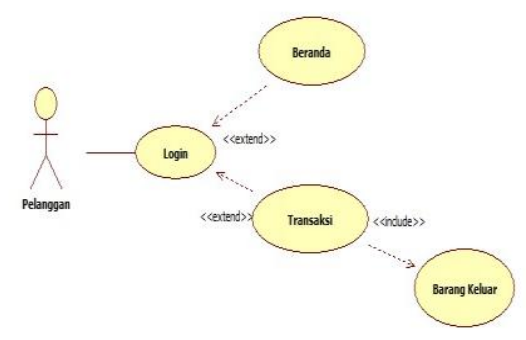

Gambar 4. Use Case Diagram Pelanggan

Hasil dari penelitian ini adalah sebuah sistem informasi inventory di CV. Wijaya Parfum Laundry. sistem ini dapat memberikan informasi mengenai stok barang yang ada di CV. Wijaya Parfum Laundry. Dengan begitu sistem ini dapat memudahkan admin untuk mendata stok barang yang ada. Berikut merupakan tampilan halaman sistem informasi inventory parfum laundry di CV.Wijaya :

1. Tampilan Halaman Login Admin

Tampilan halaman login admin merupakan halaman yang pertama kali diakses oleh admin yang sudah teregistrasi.

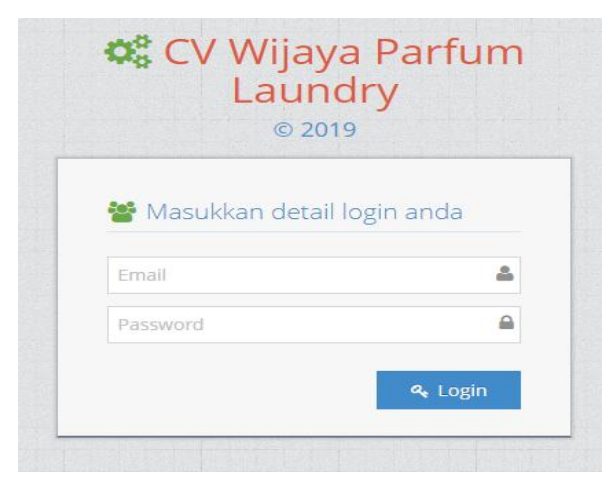

Gambar 4. Tampilan Halaman Login Admin, Karyawan dan Pelanggan 
2. Tampilan Halaman Utama Admin (Dashboard)

Tampilan halaman admin merupakan tampilan yang hanya bias diakses admin dan terdapat berbagai pilihan menu untuk mengelola website.

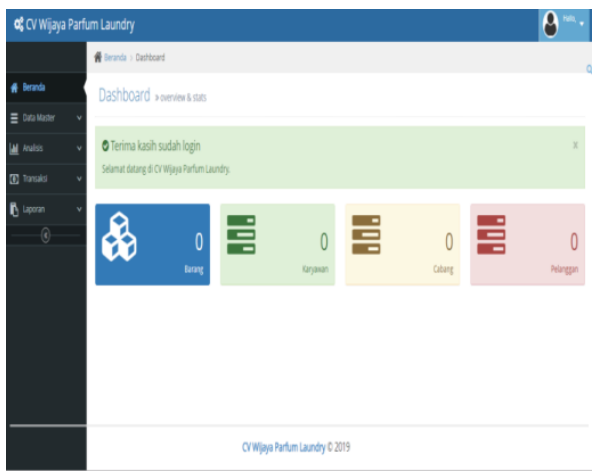

Gambar 5. Tampilan Halaman Utama Admin

3. Tampilan Halaman Tambah Data Barang

Tampilan halaman tambah data barang digunakan untuk menginput barang yang ada di CV. Wijaya parfum Laundry.

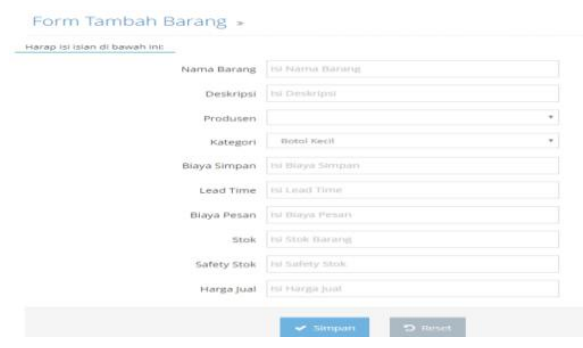

Gambar 6 Tampilan Halaman Tambah Data Barang

4. Tampilan Halaman Data Barang

Tampilan halaman data barang digunakan untuk menampilkan seluruh data yang ada di CV. Wijaya Parfum Laundry.

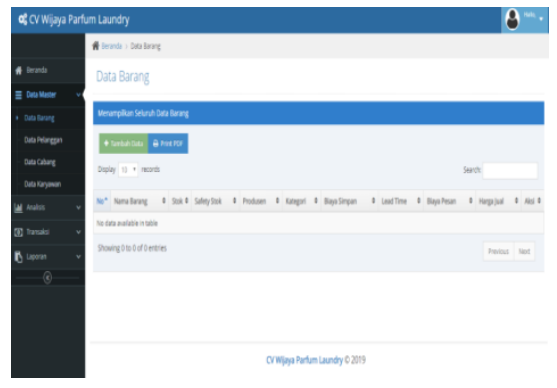

Gambar 7 Tampilan Halaman Data Barang

5. Tampilan Halaman Tambah Data Pelanggan

Tampilan halaman tambah data pelanggan digunakan untuk menambah data konsumen yang order di CV. Wijaya Parfum Laundry.

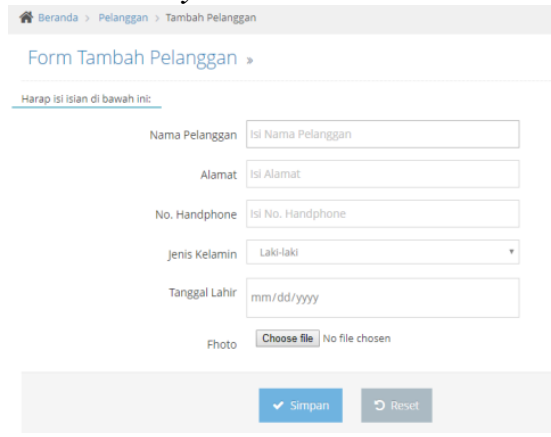

Gambar 8 Tampilan Halaman Tambah Data Pelanggan

6. Tampilan Halaman Data Pelanggan

Tampilan halaman data pelanggan digunakan untuk menampilkan seluruh data milik pelanggan yang ada di $\mathrm{CV}$. Wijaya Parfum Laundry.

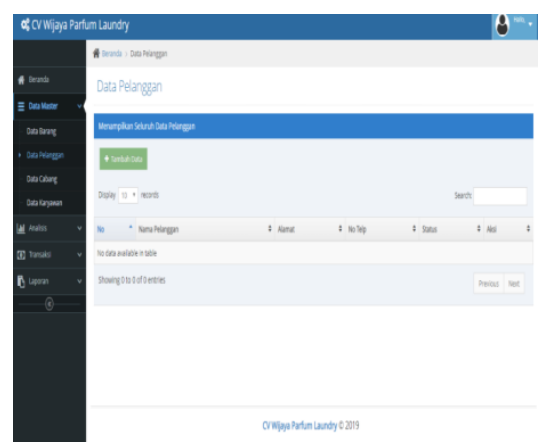

Gambar 9 Tampilan Halaman Data Pelanggan

7. Tampilan Halaman Tambah Data Cabang Tampilan halaman tambah data cabang digunakan untuk menambahkan data cabang di berbagai kota yang ada di CV. Wijaya Parfum Laundry. 
Nin Beranda, Cabarg , Tambah cabang

Form Tambah Cabang *

Harap isi ssan di bawah ink

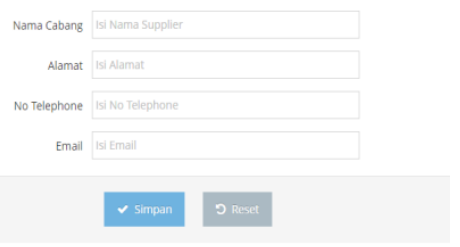

Gambar 10 Tampilan Halaman Tambah Data Cabang

8. Tampilan Halaman Data Cabang

Tampilan halaman data cabang digunakan untuk menampilkan seluruh data cabang yang ada di CV. Wijaya Parfum Laundry.

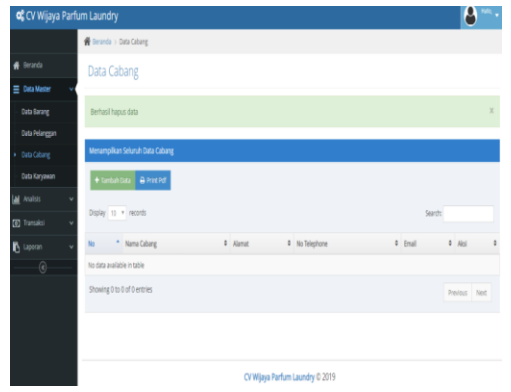

Gambar 11 Tampilan Halaman Data Cabang

9. Tampilan Halaman Tambah Data Karyawan

Tampilan halaman tambah data karyawan digunakan untuk menambahkan data karyawan di CV. Wijaya Parfum Laundry.

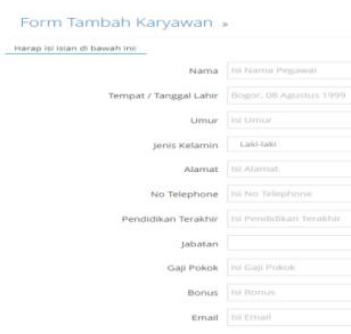

Gambar 12. Tampilan Halaman Tambah Data Karyawan

10. Tampilan Halaman Data Karyawan

Tampilan halaman data karyawan digunakan untuk menampilkan seluruh data karyawan yang bekerja di CV. Wijaya Parfum Laundry.

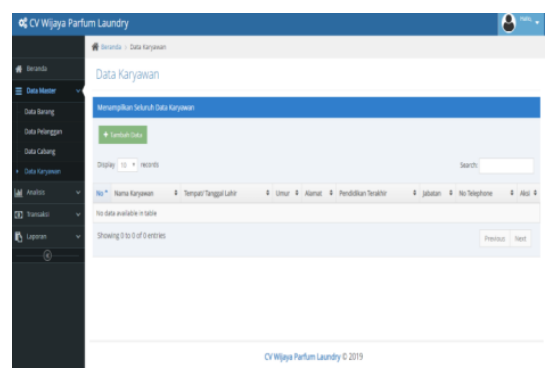

Gambar 13. Tampilan Halaman Data Karyawan

11. Tampilan Halaman Tambah Transaksi Barang Masuk

Tampilan halaman tambah transaksi barang masuk digunakan untuk menambahkan jumlah barang di CV. Wijaya Parfum Laundry.

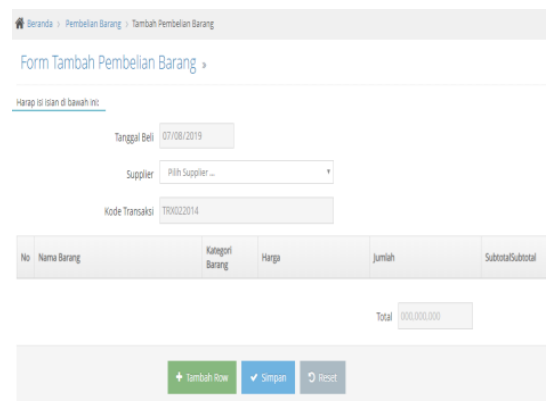

Gambar 14. Tampilan Halaman Tambah Transaksi Barang Masuk

12. Tampilan Halaman Transaksi Barang Masuk

Tampilan halaman transaksi barang masuk digunakan untuk menampilkan seluruh data transaksi yang ada di CV. Wijaya Parfum Laundry.

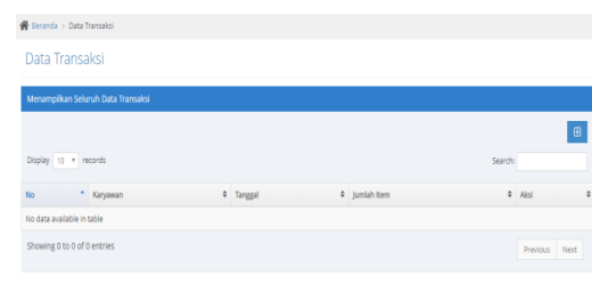

Gambar 15. Tampilan Halaman Transaksi Barang Masuk 
13. Tampilan Halaman Tambah Transaksi Barang Keluar

Tampilan Halaman Tambah Transaksi Barang Keluar digunakan untuk menambahkan transaksi penjualan di CV. Wijaya Parfum Laundry.

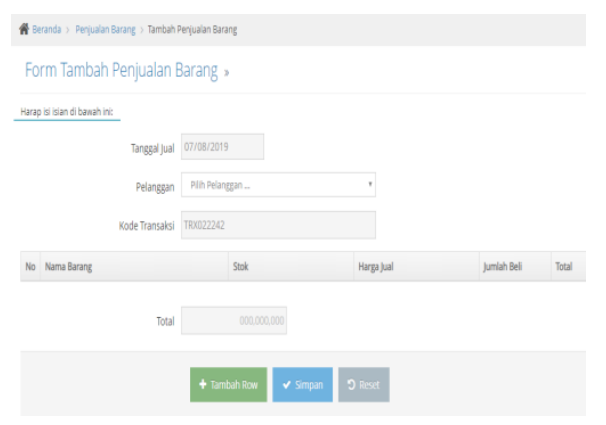

Gambar 16. Tampilan Halaman

Tambah Transaksi Barang Keluar

14. Tampilan Halaman Transaksi Barang Keluar

Tampilan halaman transaksi barang keluar digunakan untuk menampilkan seluruh data transaksi barang keluar yang ada di CV. Wijaya Parfum Laundry.

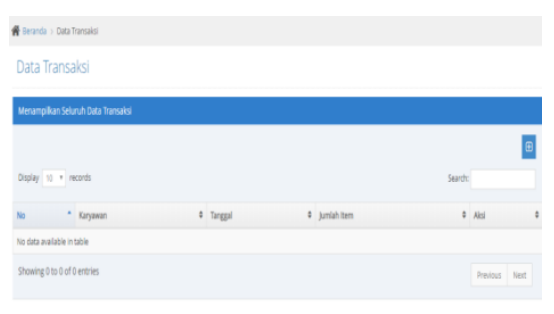

Gambar 17. Tampilan Transaksi Barang Keluar

15. Tampilan Halaman Laporan Penjualan Tampilan halaman laporan penjualan digunakan untuk menampilkan seluruh data penjualan di CV. Wijaya Parfum Laundry.
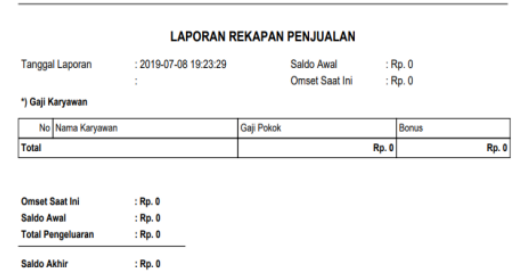

Gambar 18. Tampilan Halaman Laporan Penjualan

\section{KESIMPULAN}

Sistem informasi inventory yang dibangun meliputi proses pemesanan, transaksi barang masuk dan barang keluar. Sistem ini mempermudah karyawan dalam proses pengecekan barang, pendataan barang masuk dan barang keluar.

\section{DAFTAR PUSTAKA}

Connolly, T., Begg, C, 2010, Database Systems: A Practical Approach To Design, Implementation, And Management. 5th Edition. Pearson Education

Dwitama, Y. 2017, Sistem Informasi Terkomputerisasi Pada Sistem Persediaan Perusahaan Jasa Laundry (Studi Kasus Pada Garden Eco Laundry), online. http://repository.wima.ac.id/13485/

Ladjamudin, Al-Bahra Bin, (2006), Analisis dan Desain Sistem Informasi, Graha Ilmu :Yogyakarta.

Minarni, 2014, Sistem Informasi Inventory Obat pada Rumah Sakit Umum Daerah Padang, Volume 16, No.1.

Sukamdana, B. 2011, Perancangan Sistem Informasi Inventory Berbasis Web pada PT. Citra Gemilang Prima. Online. https://digilib.esaunggul.ac.id/perancanga $\mathrm{n}$-sistem-informasi-inventory-berbasisweb-pada-pt-citra-gemilang-prima8429.html 